\title{
A atuação dos assistentes sociais nos órgãos municipais de Proteção e Defesa Civil
}

Social workers in civil defense and protection municipal public bodies

\author{
Adriana Soares Dutra* \\ Rafael Soares Gonçalves**
}

\begin{abstract}
Resumo - Nas últimas décadas, situações de desastre têm se tornado cada vez mais comuns no Brasil. Reflexo de uma política de descaso, especialmente com a população mais pobre, que vem sendo afetada de forma severa, desastres e riscos têm surgido como temas relevantes a serem estudados por várias áreas de conhecimento. Tendo isso em vista, o presente artigo pretende analisar o caso específico do Serviço Social. A partir da coleta de dados dos órgãos municipais de Proteção e Defesa Civil de 142 municípios brasileiros, por meio de questionários digitais, buscou-se conhecer alguns aspectos da atuação de assistentes sociais na gestão de riscos e desastres. Constatou-se, assim, a precariedade das defesas civis, a ausência de profissionais do Serviço Social nesses espaços e uma demanda da atuação que se concentra no período pós-impacto, levando a atuações pontuais e fragmentadas. Palavras-chave: proteção; Defesa Civil; Serviço Social; atribuições profissionais.
\end{abstract}

\begin{abstract}
Disaster situations have become increasingly common in Brazil in recent decades as a result of neglect policies. It is especially hard on the poor population, the most affected demographic. Disasters and risks have emerged as relevant study topics in various areas, and this article analyzes the specific case of the field of social work. Based on data collected through digital questionnaires from 142 Brazilian civil defense and protection municipal public bodies, it sought to meet some aspects of the performance of social workers in the management of risks and disasters. It noted the presence of the precariousness in civil defense, the absence of social work professionals, and a demand for action focusing on the post-impact period, which leads to occasional and fragmented interventions.
\end{abstract}

Keywords: safety; civil defense; social work; professional duties.

\footnotetext{
* Doutoranda do Programa de pós-graduação do Departamento de Serviço Social da Pontifícia Universidade Católica do Rio de Janeiro. Exerce suas atividades laborais na Petrobras, na área de Responsabilidade social e contingência com comunidades. Correspondência: PUC-Rio - Departamento de Serviço Social: Rua Marquês de São Vicente, 225, Gávea - Rio de Janeiro, RJ - Brasil. CEP: 22451-900. Email: <adriana_soares_dutra@hotmail.com>

** Pós-doutor pelo Laboratório de Antropologia da escrita da École des Hautes Études en Sciences Sociales - EHESS (2008). Professor adjunto do Departamento de Serviço Social da Pontifícia Universidade Católica do Rio de Janeiro. Jovem Cientista do Nosso Estado pela FAPERJ (2012-2014/2015-2017) e bolsista de produtividade do CNPQ (PQ 2-CA Psicologia/Serviço Social). Correspondência: PUC-Rio - Departamento de Serviço Social: Rua Marquês de São Vicente, 225, Gávea - Rio de Janeiro, RJ - Brasil. CEP: 22451-900. Email: <rafaelsgoncalves@yahoo.com.br>
} 


\section{Introdução}

No debate sobre riscos e desastres no Brasil, a fragilidade da Política de Proteção e Defesa Civil apresenta-se como um dos aspectos mais relevantes. Seja na análise dos processos que desencadeiam os desastres, seja na própria política pública, a ausência de recursos e de profissionais, assim como a falta de capacitação e de estrutura, têm levado vários autores a jogarem luz sobre essa questão (VALENCIO et al., 2009; VALENCIO, 2010, 2012; SIENA, 2012; SANTOS, 2012).

Essa preocupação se origina, em grande medida, dos trabalhos de campo realizados por esses estudiosos, que passam por uma observação cuidadosa e de longo prazo sobre a forma de atuação, as dificuldades encontradas e as interferências políticas existentes. Porém, ainda carecemos de dados objetivos sobre o campo. A ausência de informações sistematizadas e a dificuldade em acessar os poucos dados existentes ainda se configuram como limitadores para o avanço da pesquisa na área.

Tal realidade se estende ao trabalho dos assistentes sociais. Pouco se sabe sobre o cotidiano de trabalho dos profissionais que desenvolvem suas atividades laborais em instituições de Proteção e Defesa Civil no país. Além disso, a precariedade destes órgãos e a complexidade das situações enfrentadas levam à convocação de profissionais lotados em outros espaços ocupacionais, gerando obstáculos ainda maiores para o conhecimento sobre esse fazer.

Um olhar para o Serviço Social demonstra que a produção atualmente disponível, quando se aproxima dos temas em questão, tem sido predominantemente realizada pelas áreas da Saúde (VASCONCELOS, 2007) e da Assistência Social (COUTO et al., 2014), nas quais a emergência, os riscos e a vulnerabilidade tornam-se objeto de conhecimento sob óticas determinadas. Em que pese à importância desse conhecimento, fica evidente a necessidade de estudos que busquem abordar aspectos mais abrangentes referentes aos riscos e aos desastres. Algumas iniciativas nesta direção encontram-se em Vargas (2006, 2013, 2015), Siena (2012) e Santos et al. (2014), no entanto, ainda há muitos avanços a serem feitos, especialmente no que tange à atuação profissional propriamente dita.

Torna-se extremamente importante pesquisar os espaços e a forma de atuação do assistente social na gestão de riscos e desastres para melhor compreender as suas múltiplas determinações. A apropriação deste debate é fundamental para que a atuação profissional ocorra em consonância com o Projeto Ético-Político Profissional, contribuindo para a sua real qualificação e visibilidade. Nas palavras de Netto (2009, p. 33), "do conhecimento não se extraem diretamente indicativos para a ação, para a prática profissional e interventiva. Mas não se terá uma prática eficiente e inovadora se ela não estiver apoiada em conhecimentos sólidos e verazes". 
Diante da necessidade apontada, no âmbito das pesquisas doutorais da primeira autora e com a orientação do segundo autor, foi realizada uma pesquisa quantitativa, visando à aproximação com questões referentes à estrutura dos órgãos municipais de Proteção e Defesa Civil do país. Buscouse conhecer aspectos referentes à sua dimensão, à presença ou não de assistentes sociais em suas equipes, à existência de demanda para atuação de assistentes sociais de outros órgãos ou instituições e, por fim, às atribuições postas a esses profissionais.

O questionário digital utilizado contou com 10 questões, sendo 9 fechadas e uma aberta; foi direcionado a profissionais lotados em órgãos de Proteção e Defesa Civil municipais. Disponibilizado pela internet, seu link foi enviado para, aproximadamente, 1.000 contatos pessoais e institucionais, acompanhado de uma mensagem contendo uma breve explicação sobre o estudo.

Ao final de dois meses (julho a setembro de 2015), obtivemos um total de 172 respostas. Deste universo, 30 foram descartadas: por se tratar de uma pesquisa direcionada às instituições municipais de Proteção e Defesa Civil e não aos profissionais individualmente, a duplicidade de informações levaria a um problema metodológico. Sendo assim, nos casos em que mais de um questionário foi respondido, tendo como base um mesmo município/ instituição, optou-se pela inclusão de apenas uma das respostas na base de dados. As demais foram excluídas.

O resultado final considerou as informações de 142 municípios, distribuídos em todas as cinco regiões do país e alcançando um total de 24 estados, além do Distrito Federal. A partir da análise desses dados, o presente artigo tem como proposta realizar, primeiramente, um breve histórico sobre a estruturação da Defesa Civil no Brasil; posteriormente, serão feitas algumas considerações sobre a atuação do Serviço Social na área de riscos e de desastres e, por fim, relacionaremos aspectos desses dois universos com os dados coletados na pesquisa.

\section{A Defesa Civil no Brasil}

A estruturação da Defesa Civil tem início em meados do século XX, mais especificamente no ano de 1942. Inspirado no modelo da Inglaterra, que um ano antes havia instituído o Civil Defense Service, o governo de Getúlio Vargas criou o Serviço de Defesa Passiva Antiaérea'. O serviço, voltado para o atendimento aos impactos, impôs à população medidas que deveriam ser adotadas em casos de "emergência". A regulamentação

\footnotetext{
${ }^{1}$ A criação de serviços de Defesa Civil motivada pela participação na Segunda Guerra Mundial é uma característica também encontrada em outros países. Um exemplo é a Argentina. Sobre este assunto, ver: Natenzon e Viand (2008).
} 


\section{ADVistg all paUtg}

\} A ATUAÇÃO DOS ASSISTENTES SOCIAIS - DUTRA, A. S.; GONÇALVES, R. S. \}

DOI: $10.12957 /$ REP.2016.25388

do Serviço de Defesa Civil Antiaérea só ocorreu um ano depois, com a aprovação do Decreto Federal no 12.628 de 17 de junho de 1943, que definia como sua finalidade: "estabelecer métodos e precauções de segurança para proteção moral e da vida da população, proteção ao patrimônio material, cultural e artístico da Nação" (BRASIL, 1943a).

Por meio do Decreto-Lei no 5.861, do mesmo ano, o Serviço de Defesa Passiva Antiaérea passou a ser denominado Serviço de Defesa Civil (BRASIL, 1943b). O referido decreto modificou também a nomenclatura da então Diretoria Nacional de Defesa Passiva Antiaérea, que passou a se chamar Diretoria Nacional do Serviço de Defesa Civil. Em 1946, com o fim da guerra, o serviço foi completamente desativado.

Aproximadamente 20 anos depois, as enchentes de 1966, ocorridas no então estado da Guanabara, motivaram a instauração do Grupo de Estudos da "Mobilização dos órgãos estaduais para prevenir consequência de catástrofes". Este grupo foi responsável pela elaboração de um Plano Diretor de Defesa Civil. Entre as justificativas apresentadas na introdução do documento, estão:

f) Na ausência de legislação federal que fixe a organização de 'Defesa Civil' no País, com a discriminação detalhada do que compete aos Estados membros da Federação, não deve evidentemente a Guanabara pretender criá-la em todo o conjunto de sua estrutura, funções, métodos e programas.

[...]

h) A calamidade que se abateu sobre o Estado, em janeiro do corrente ano, com perdas de vidas e grandes danos, obrigou o Governo Estadual e a população a improvisarem uma verdadeira ação de 'Defesa Civil', a fim de enfrentarem as graves conseqüências do temporal, as quais certamente se agravaram em virtude da absoluta falta de planos preestabelecidos. Esta dura experiência indicou ao Governo da Guanabara a necessidade imperiosa de estabelecer um mínimo de planejamento para situações dessa natureza. (RIO DE JANEIRO, 1999, p. 54).

É nesse contexto de impactos e inanição da União que, no ano de 1966, foi criada a Comissão Central de Defesa Civil (Cedec), primeira Defesa Civil estadual do país. Além da criação da Cedec, o Plano Diretor previa:

- a colaboração de órgãos e entidades externos ao Estado;

- a utilização de serviços voluntários e sua capacitação;

- a participação e atribuições de vários setores, como da assistência social;

- a criação das comissões regionais de Defesa Civil (Redec).

No ano seguinte, em 1967, foi criada a Comissão Permanente de Defesa Civil (CPDC), que previa, entre outras questões, a criação dos núcleos municipais de Defesa Civil (Nudec), que podem ser considerados, até hoje, 


\section{ReVistg ell pautg}

\} A ATUAÇÃO DOS ASSISTENTES SOCIAIS - DUTRA, A. S.; GONÇALVES, R. S. \}

DOI: $10.12957 /$ REP. 2016.25388

a menor célula da estrutura da Defesa Civil2. Em 1969, finalmente foi criado um grupo de trabalho (GT) de abrangência nacional, coordenado pelo Ministério do Interior. A este GT foi dada a atribuição de elaborar um plano nacional de defesa permanente contra calamidades públicas (BRASIL, 1969).

Nesse período, foi criado um conjunto de normas voltado para a estruturação da Defesa Civil no país. Entre as ações realizadas, podemos destacar a instituição do Fundo Especial para Calamidades Públicas (Funcap), criado com o objetivo de arrecadar recursos para a assistência a populações atingidas.

Esse movimento teve continuidade na década de 1970 com a criação do Grupo Especial para Assuntos de Calamidades Públicas (Geacap), ligado ao Ministério do Interior e considerado o embrião da Secretaria Especial de Defesa Civil (Sedec), criada nove anos depois (UFSC, 2013), por meio do Decreto-Lei federal $n^{\circ}$ 83.839/79. A finalidade da Sedec, descrita no mencionado decreto-lei, era de:

Exercer, em todo o Território Nacional, a coordenação das atividades relativas às medidas preventivas, assistenciais e de recuperação dos efeitos produzidos por fenômenos, adversos de quaisquer origens, bem como aquelas destinadas a preservar a moral da população e o restabelecimento da normalidade da vida comunitária. (BRASIL, 1979, grifos nossos).

É possível verificar que, a partir deste momento, começam a figurar nos documentos elaborados pela Defesa Civil questões voltadas para prevenção e recuperação. Até àquele momento, expressões como calamidades públicas, catástrofes e socorro eram utilizadas quase que exclusivamente para referenciar ações de Defesa Civil, demonstrando a ênfase na resposta.

Apenas no final da década de 1980, após a promulgação da Constituição Federal de 1988 e a responsabilidade atribuída à União de legislar sobre Defesa Civil, foi criado o Sistema Nacional de Defesa Civil (Sindec), com objetivo de:

Planejar e promover a defesa permanente contra calamidades públicas (artigo 21, inciso XVIII da Constituição), integrando a atuação dos órgãos e entidades públicas e privadas que, no território nacional, exercem atividades de planejamento, coordenação e execução das medidas de assistência às populações atingidas por fatores anormais adversos, bem assim a prevenção ou reparação de danos em situação de emergência ou estado de calamidade pública.

[...]

Parágrafo único - Para o efeito deste Decreto, considera-se:

${ }^{2}$ Decreto estadual no 13.002 de 28 de setembro de 1967 (RIO DE JANEIRO, 1999, p. 88). 


\section{ADVistg all paUtg}

\} A ATUAÇÃO DOS ASSISTENTES SOCIAIS - DUTRA, A. S.; GONÇALVES, R. S. \}

DOI: $10.12957 /$ REP.2016.25388

a) Defesa Civil - o conjunto de medidas destinados a prevenir, limitar ou corrigir os riscos e danos pessoais e materiais decorrentes de estado de calamidade pública ou de situação de emergência. (BRASIL, 1988).

Alguns anos mais tarde, a Organização das Nações Unidas (ONU) instituiu a Década Internacional de Redução de Desastres Naturais, compreendendo o período entre 1990 e 1999. A iniciativa teve como principal objetivo minimizar perdas de vidas, danos e transtornos sociais e econômicos decorrentes de desastres. Na esteira dessa iniciativa, mais precisamente no ano de 1994, o governo brasileiro, por determinação do Ministério da Integração Nacional, elaborou a Política Nacional de Defesa Civil (PNDC).

Em virtude do aumento abrupto dos desastres naturais a partir da década de 50, a ONU criou uma secretaria denominada United Nations Disaster Relief Organization (UNDRO) que buscou propor e promover iniciativas preventivas e mitigadoras em desastres naturais para todo o mundo. Para tanto, na Assembléia Geral das Nações Unidas de 11 de dezembro de 1987 foi decidido, por unanimidade, que os anos 90 seriam a Década Internacional para a Redução de Desastres Naturais (International Decade for Natural Disaster Reduction - IDNDR). O sucesso desse esforço é reconhecido por alguns e contestado por outros [...]. (MARCELINO; NUNES; KOBIYAMA, 2006, p. 135).

Durante esse período, a coordenação da Defesa Civil já esteve sob a responsabilidade de diferentes ministérios. Na medida em que novas pastas foram criadas, o atendimento às populações atingidas por calamidades, a assistência aos municípios e as obras de proteção, entre outras atribuições, também migraram. Com a criação do Ministério da Integração Nacional, no ano de 1999, as ações de Defesa Civil passaram a ser de responsabilidade deste órgão.

Quanto ao Sistema Nacional de Defesa Civil, este passou por uma série de reformulações desde que foi instituído. Atualmente, vigora a configuração definida pelo Decreto Federal $n^{\circ} 7.257$ de 10 de dezembro de 2010, o qual define que o Sindec tem como objetivo "planejar, articular e coordenar as ações de Defesa Civil em todo o território nacional". Além disso, também define, no artigo $5^{\circ}$, que o "SINDEC será composto pelos órgãos e entidades da União responsáveis pelas ações de Defesa Civil, bem como pelos órgãos e entidades dos Estados, Distrito Federal e Municípios que a ele aderirem" (BRASIL, 2010).

"Apesar dos avanços alcançados durante décadas, o Brasil ainda carecia de uma legislação mais abrangente, capaz de consolidar o tema na agenda pública nacional" (DUTRA; DALCIN, 2015, p. 228). Sendo assim, mais recentemente, assistimos à criação da Lei Federal no 12.608/12. Com a sua aprovação, o termo proteção foi incorporado e o sistema passou a ser denominado Sistema Nacional de Proteção e Defesa Civil (Sinpdec). A lei 


\section{ReVistg all pautg}

\} A ATUAÇÃO DOS ASSISTENTES SOCIAIS - DUTRA, A. S.; GONÇALVES, R. S. \}

DOI: $10.12957 / R E P .2016 .25388$

ainda prescinde de regulamentação; por essa razão, até o momento, o Sinpdec continua funcionando com base na reformulação supramencionada de 2010. Assim como já estava presente em legislações anteriores, a responsabilidade pelo atendimento inicial permanece sendo dos municípios; as demais esferas devem ser acionadas para apoio.

Como procuramos demonstrar brevemente, muitas mudanças ocorreram desde as primeiras iniciativas de estruturação da Defesa Civil. Todavia, a realidade ainda apresenta grandes desafios a serem superados. O sistema de Defesa Civil brasileiro vem sendo bastante criticado no campo das Ciências Sociais. Valencio (2010, p. 75) questiona a sua capacidade de garantia do direito à vida, uma vez que seu modelo verticalizado "age com baixa flexibilidade, conta com reduzida confiança junto aos grupos sociais em risco ou afetados e é impermeável às demandas, direitos e pontos de vista dos grupos que vivenciam reiteradamente os desastres". Sobre o desenho atual da Política Nacional de Proteção e Defesa Civil, a autora enfatiza, entre outras questões, a ausência de alterações significativas na sua estrutura, o que acaba por limitar ou mesmo invalidar alguns movimentos de mudança. Especificamente em relação à inclusão do termo proteção no Sistema (Sinpdec), ela afirma tratar-se de um jogo dos desamparados, e conclui:

Dá-se continuidade a esse jogo, na promoção de uma nova onda de atualizações aparentes, agora, substituindo a designação defesa civil pela de proteção civil no desenho do sistema nacional, deixando intocados os atores em posição de poder, os métodos de construção da política e as formas de acesso aos recursos. (VALENCIO, 2012, p. 130).

A análise dos resultados da pesquisa demonstra alguns desses aspectos, como poderemos ver a seguir.

\section{Os órgãos municipais de Proteção e Defesa Civil}

De acordo com o Sinpdec, os órgãos municipais de Proteção e Defesa Civil são responsáveis pela articulação, coordenação e execução do sistema em nível municipal. As Coordenadorias de Proteção e Defesa Civil (Compdec) devem atuar em todas as fases do desastre (prevenção, mitigação, preparação, resposta e recuperação) e receber apoio dos órgãos estaduais e da União, quando necessário.

Informação obtida junto à Secretaria Nacional de Proteção e Defesa Civil (Sedec) aponta para a existência de $3.318^{3}$ Compdec no Brasil. Além de este total não alcançar $60 \%$ do total de municípios do país, a realidade encontrada em grande parte das Compdec se apresenta como

${ }^{3}$ Informação obtida por meio da Lei de Acesso à Informação (LAI), em 7 de outubro de 2015. 


\section{ReVistg all pavtg}

\} A ATUAÇÃO DOS ASSISTENTES SOCIAIS - DUTRA, A. S.; GONÇALVES, R. S.\}

DOI: $10.12957 /$ REP.2016.25388

limitadora e, por vezes, impeditiva para a realização das atribuições que Ihe são confiadas.

Reportagem do jornal O Estado de São Paulo, publicada em 15 de janeiro de 2011, traz à tona a inexistência de uma política de proteção do Estado brasileiro. A reportagem cita um relatório entregue à ONU pela Sedec referente à implementação do Plano Nacional de Redução do Impacto de "Desastres Naturais": "A maioria dos órgãos que atuam em defesa civil está despreparada para o desempenho eficiente das atividades de prevenção e de preparação" (O ESTADO DE SÃO PAULO, 2011). Praticamente um a cada quatro municípios do país sequer tem um serviço de Defesa $\mathrm{Ci}$ vil e, onde existe, não há como medir se é eficiente. Em outro trecho da matéria, a afirmação segue na mesma direção:

Em 2009, o número de órgãos municipais criados oficialmente no Brasil (para lidar com desastres) alcançou o percentual de $77,36 \%$ dos municípios brasileiros, entretanto, não foi possível mensurar de forma confiável o indicador estabelecido como taxa de municípios preparados para prevenção e atendimento a desastres. (O ESTADO DE SÃO PAULO, 2011).

Passados mais de quatro anos desde a reportagem, verifica-se que pouca coisa se modificou. No que se refere aos dados quantitativos coletados na pesquisa que estamos realizando, na maior parte dos municípios que fizeram parte da amostra, a criação das Compdec se concentra entre os anos de 1995 e 2015, em especial entre 2005 e 2015, mostrando o quanto é recente a estruturação do serviço no país, como demonstra o gráfico 1.

\section{Gráfico 1 \\ Período de criação dos órgãos municipais de Proteção e Defesa Civil}

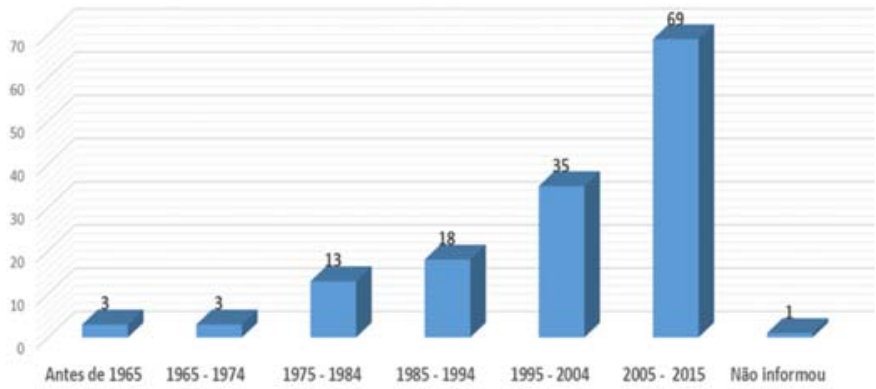

Em relação ao número de profissionais, não são raros os casos em que o funcionamento dos órgãos municipais de Defesa Civil ocorre com 
equipes absolutamente reduzidas. Muitas vezes, um único profissional tornase responsável por todas as ações cotidianas de Defesa Civil do município e se percebe sem condições objetivas de atendimento às demandas existentes. Num um universo de 142 municípios, 70 afirmaram operar com até 5 profissionais, ou seja, 49\%. Ressalta-se que este número inclui tanto o secretário ou o coordenador, quanto profissionais administrativos que atuam nas equipes.

\section{Gráfico 2 \\ Número de profissionais que compõem as equipes municipais de Proteção e Defesa Civil}

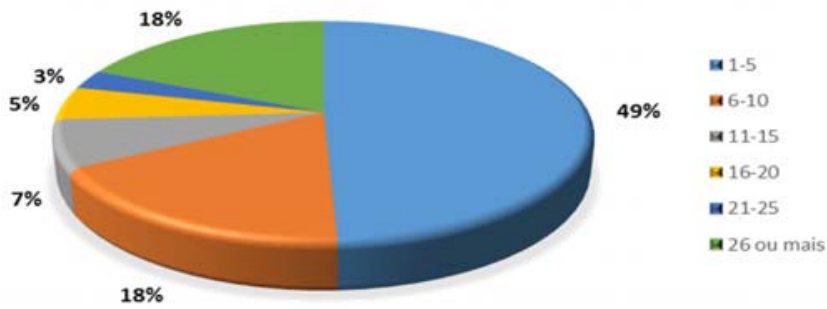

Apesar de a pesquisa não ter atingido este nível de aprofundamento, sabe-se também que são comuns os casos em que as atribuições de proteção e defesas civis se juntam a outras, formando uma só secretaria ou coordenadoria. Tal aspecto foi observado em visitas realizadas a cinco órgãos municipais de Defesa Civil do estado do Rio de Janeiro ${ }^{4}$. A ausência de salas, de equipes, de equipamentos e de capacitação faz parte do cotidiano de alguns dos municípios visitados. Verificou-se que alguns órgãos foram criados somente após a ocorrência dos impactos causados na região serrana do estado, em janeiro de 2011, e que o funcionamento ocorre em condições absolutamente precárias. Trata-se de uma realidade que dificulta consideravelmente a realização de um trabalho consistente da Defesa Civil, especialmente no que se refere às ações de prevenção e mitigação.

Embora esses números chamem a atenção, é importante sinalizar também que 27 municípios ( $23 \%$ dos respondentes) indicaram que as equipes são compostas por 26 ou mais profissionais, o que pode significar um avanço no que se refere à política de Defesa Civil. No entanto, ao cruzarmos essa informação com a origem do município respondente, observase que essa realidade corresponde, em grande medida, às capitais dos estados. Quando se trata dos demais municípios, o que se verifica é que, na

\footnotetext{
${ }^{4}$ As visitas compõem estudo mais aprofundado, referente ao doutoramento de uma das autoras, e serão melhor analisadas para este fim.
} 


\section{ADVistg all paUtg}

\} A ATUAÇÃO DOS ASSISTENTES SOCIAIS - DUTRA, A. S.; GONÇALVES, R. S. \}

DOI: $10.12957 /$ REP.2016.25388

maioria, são locais com históricos recorrentes de impactos, como é o caso de Petrópolis, Nova Friburgo e Angra dos Reis. Outro aspecto que chama a atenção é o fato de estarem localizados na Região Sudeste, em especial no estado do Rio de Janeiro, o que pode ser considerado um indicativo da desigualdade na Defesa Civil enquanto política pública no território nacional.

Retomando as atribuições postas às Compdec, encontramos a de fomentar a criação dos Núcleos de Defesa Civil Comunitários (Nudec), hoje denominados Núcleos de Proteção e Defesa Civil (Nupdec). Considerado o principal elo entre a população e os órgãos governamentais, a última informação disponível no site da Secretaria Nacional de Defesa Civil indicava que a existência desses núcleos estava limitada a 16 municípios, incluindo o Distrito Federal ${ }^{5}$. O problema é agravado pela falta de informações em relação a esses serviços. Para a elaboração deste artigo, não foram encontradas informações atualizadas sobre o número de Nupdec existentes no Brasil. Além disso, até meados de 2014, a Secretaria Nacional de Proteção e Defesa Civil (Sedec) sequer dispunha de cadastro com informações básicas sobre os órgãos municipais de Proteção e Defesa Civil no país. Quando a mesma informação foi solicitada aos órgãos estaduais, apenas três demonstraram condições de atendimento à demanda.

Ainda no que se refere à estrutura dos órgãos de Proteção e Defesa Civil, em relação à composição das equipes, destaca-se a forte presença de militares na formação de seus quadros. Esta realidade, já amplamente discutida nos estudos de Valencio et al. (2009) e Valencio (2012), também é percebida quando se observa o estreito vínculo entre o Corpo de Bombeiros e os órgãos de Defesa Civil.

Ao analisar a estruturação da Defesa Civil no estado do Rio de Janeiro, o documento Histórico e evolução da Defesa Civil no Brasil, do Governo do Estado do Rio de Janeiro (1999), aponta para a sobreposição de funções, ou seja, profissionais do Corpo de Bombeiros eram nomeados para cargos de chefia na Defesa Civil estadual. Na apresentação dos decretos estaduais no 11 de 15 de março de 1975, e no 4.691 de 14 de outubro de 1981, ambos referentes à estrutura da Secretaria de Segurança Pública do Estado do Rio de Janeiro, o documento chama a atenção para o seguinte fato: "a figura do Comandante-Geral do Corpo de Bombeiros era também a do Diretor - Geral do Departamento Geral de Defesa Civil" (RIO DE JANEIRO, 1999, p. 100). Essa situação ocorreu mesmo nos momentos em que a Defesa Civil e Corpo de Bombeiros estiveram no mesmo nível, ou seja, sem que houvesse submissão de um órgão ao outro, como aconteceu a partir do Decreto estadual no 4.691 de 14 de outubro de 1981. "É interessante que mesmo com a mudança de nível para o Corpo de Bombeiros, continuava sendo o seu Comandante-Geral o Diretor de Defesa Civil do Estado do Rio de Janeiro" (RIO DE JANEIRO, 1999, p. 107).

${ }^{5}$ Dados disponíveis na página do Ministério da Integração Nacional (BRASIL, 2012). 


\section{ReVistg ell pautg}

\} A ATUAÇÃO DOS ASSISTENTES SOCIAIS - DUTRA, A. S.; GONÇALVES, R. S.\}

DOI: $10.12957 / R E P .2016 .25388$

O artigo $4^{\circ}$ do Decreto estadual $n^{\circ} 7.451$ de 03 de agosto de 1984 versa sobre a estrutura básica da Secretaria de Estado da Defesa Civil do estado, e afirma que o "Secretário de Estado da Defesa Civil é o Comandante Geral do Corpo de Bombeiros do Estado do Rio de Janeiro, escolhido dentre os oficiais da ativa do último posto de Quadro de Oficiais combatentes do Corpo de Bombeiros do Estado do Rio de Janeiro" (RIO DE JANEIRO, 1999, p. 111).

Embora sejam documentos referentes às décadas de 1970 e 1980, e mais especificamente do estado do Rio de Janeiro, passados os anos, o número de militares, especialmente do Corpo de Bombeiros, cedidos para exercerem cargo de coordenadores/secretários de Defesa Civil ainda é muito significativo. Uma das evidências encontra-se na análise do cadastro das coordenadorias estaduais de Defesa Civil fornecida pela Secretaria Nacional de Proteção e Defesa Civil ${ }^{6}$. Este cadastro aponta para um número de 24 coordenadores militares, entre coronéis, tenentes e capitães etc., em sua maioria provenientes do Corpo de Bombeiros. Se, por um lado, esses coordenadores demonstram uma preparação para o atendimento em situações de impacto, por outro, questões como hierarquia, tradição e conservadorismo, fortemente disseminadas na carreira militar, são cultivadas como valores, interferindo diretamente nas formas de lidar com a população.

Outro aspecto a ser considerado em relação à presença dos militares na Defesa Civil é o foco nas ações de resposta. A realidade sugere a não superação dessa questão, haja vista a formação dos bombeiros, reconhecidamente voltada para esta fase dos desastres. Esse elemento mostra-se significativo para a análise do Serviço Social na área, nosso principal interesse.

Desde as primeiras legislações de estruturação da Defesa Civil, é possível verificar a presença da assistência social neste processo, juntamente com outras áreas atendidas pelas políticas públicas, como é o caso da Saúde e da Segurança. No entanto, verifica-se que o papel atribuído, via de regra, é o de auxiliar nas ações emergenciais. Esta questão tem rebatimentos diretos no papel da Política de Assistência Social na gestão de riscos e desastres e no Serviço Social, como trataremos a seguir.

Uma breve análise sobre a estrutura existente nos órgãos de Defesa Civil do país pesquisados confirma uma preocupação já apontada em outro ensaio: a ausência de assistentes sociais nas equipes responsáveis pela gestão de riscos e de desastres (DUTRA; DALCIN, 2015). Um percentual de $76 \%$ não conta com assistentes sociais em seus quadros, conforme apresentado no gráfico 3.

Entre as equipes que possuem assistentes sociais, o que equivale a $24 \%$ dos municípios, buscamos conhecer o número de profissionais existentes. Mais da metade indicam a existência de 5 ou mais profissionais. Este dado, obviamente, acompanha o tamanho das equipes.

${ }^{6} \mathrm{O}$ cadastro foi solicitado para pesquisa de Doutorado e disponibilizado por e-mail em 16 de maio de 2014. 


\section{ApVistg all pavtg}

\} A ATUAÇÃO DOS ASSISTENTES SOCIAIS - DUTRA, A. S.; GONÇALVES, R. S.\}

DOI: $10.12957 /$ REP.2016.25388

\section{Gráfico 3}

\section{Presença de assistentes sociais nos órgãos municipais de Proteção e} Defesa Civil

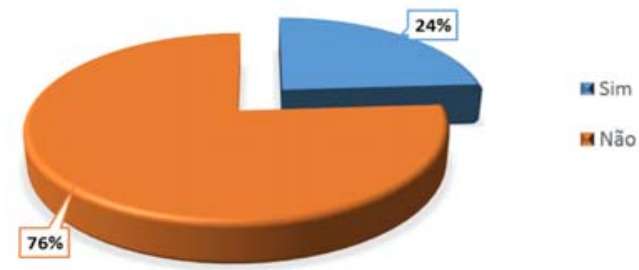

Gráfico 4

Número de assistentes sociais nos órgãos municipais de Proteção e Defesa Civil
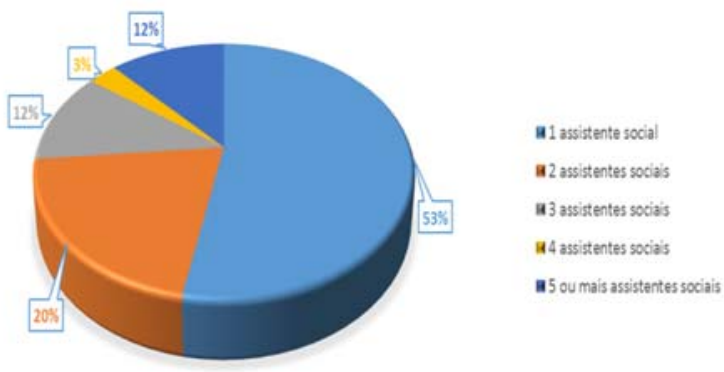

Entretanto, o fato de a maioria dos órgãos em questão não possuir assistentes sociais em seus quadros não significa a descartabilidade destes profissionais nas ações de Proteção e Defesa Civil dos municípios. A convocação de profissionais de outros órgãos para atuação em situações de riscos e de desastres ocorre com frequência e também foi apontada na pesquisa.

Um número expressivo de órgãos pesquisados, 87\%, o que corresponde a 124 municípios, afirma demandar a atuação de assistentes sociais lotados em outros equipamentos para apoiar as ações de Defesa Civil. Apenas $13 \%$, ou seja, 19 municípios, informam que não recorrem a assistentes sociais para atuação na área de riscos e desastres. Deste total, 8 possuem profissionais da área em seus quadros. 


\section{Gráfico 5 \\ Convocação de assistentes sociais de outras secretarias/órgãos/ instituições}

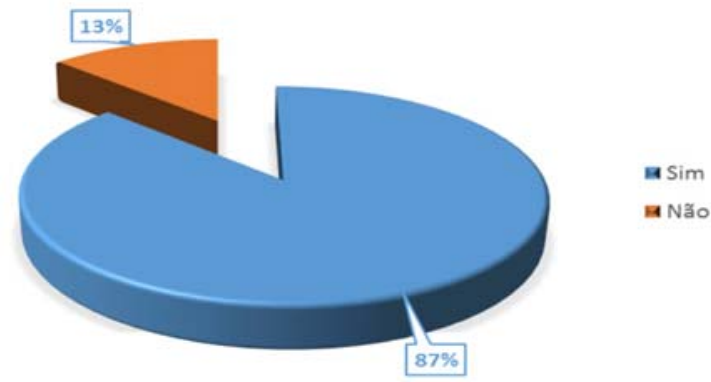

Ainda em relação aos assistentes sociais demandados a atuarem junto à Defesa Civil, verificou-se que estes estão majoritariamente lotados nas secretarias municipais de assistência social ${ }^{7}$. Outras secretarias e órgãos também comparecem no conjunto de órgãos que cedem profissionais para a atuação na área de riscos e desastres junto à Defesa Civil. No entanto, nenhum deles adquire a mesma expressão e sequer se aproximam do quantitativo indicado para as secretarias responsáveis pela política de assistência social, como é possível verificar no gráfico $6^{8}$ :

\section{Gráfico 6 - Lotação de assistentes sociais convocados pelos órgãos de Proteção e Defesa Civil}

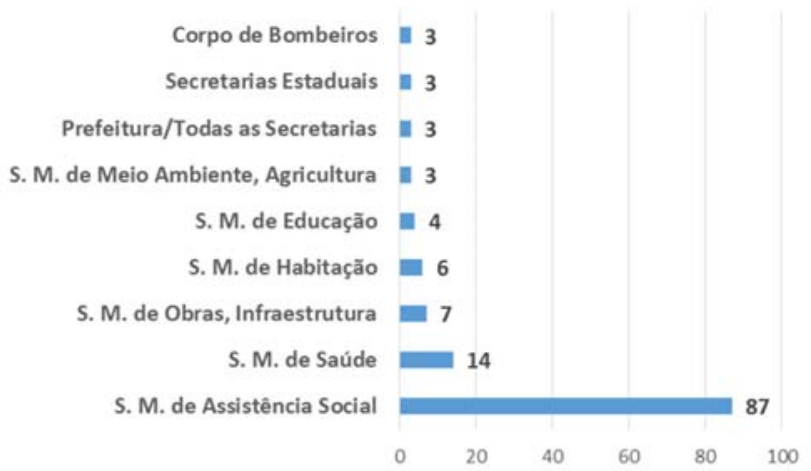

\footnotetext{
${ }^{7}$ As secretarias foram apresentadas com nomes bastante variados entre os municípios, porém, tiveram como unificador o fato de serem responsáveis pela política de assistência social desenvolvida no local.

${ }^{8}$ Para esta questão era possível marcar mais de uma alternativa, gerando um resultado de mais de $100 \%$.
} 


\section{ADVistg all paUtg}

\} A ATUAÇÃO DOS ASSISTENTES SOCIAIS - DUTRA, A. S.; GONÇALVES, R. S. \}

DOI: $10.12957 /$ REP.2016.25388

Tal realidade aponta para a importância de um olhar sobre a Política de Assistência Social e sua relação com as ações de Proteção e Defesa Civil, já que é correto afirmar que a atuação do Serviço Social se materializa na gestão de riscos e desastres, em grande medida, por meio dessa política.

A Política Nacional de Proteção e Defesa Civil (Lei 12.608/2012) abrange as ações de prevenção, mitigação, preparação, resposta e recuperação, como mencionado anteriormente ${ }^{9}$ (BRASIL, 2012). Na aplicação da pesquisa, buscou-se conhecer os momentos nos quais há atuação de assistentes sociais, de acordo com a divisão das ações. Foram obtidas as seguintes respostas: 112 indicam as ações de resposta como principal momento de atuação, seguida da recuperação (73) e da prevenção, com 70 respostas, respectivamente, como demonstra o gráfico abaixo ${ }^{10}$ :

\section{Gráfico 7 \\ Fases de atuação de assistentes sociais junto aos órgãos municipais de Proteção e Defesa Civil}

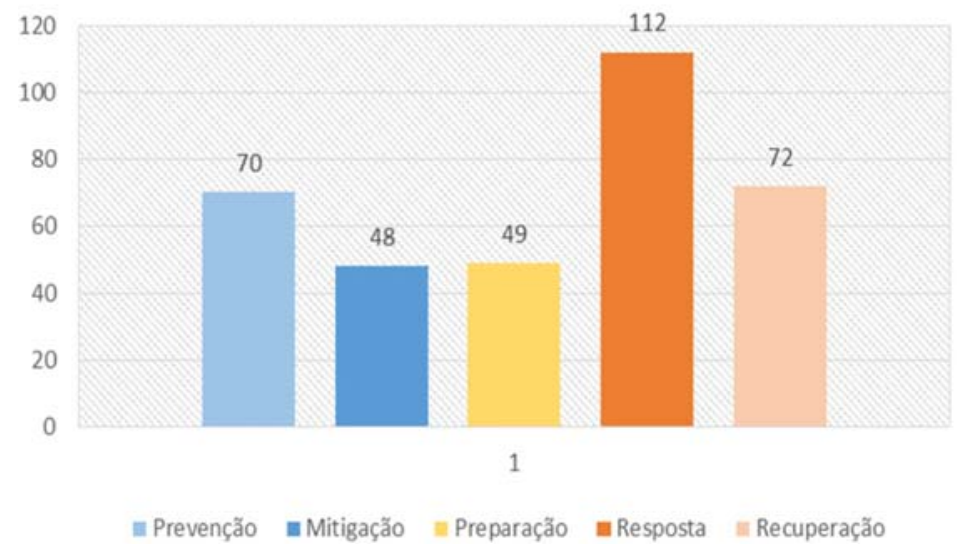

Com base nos aspectos levantados na pesquisa, parece-nos correto afirmar que esta atuação permanece direcionada, majoritariamente, para os impactos e suas consequências, distanciando-nos de uma mudança muito significativa dessa realidade até o momento. No que se refere às duas primeiras fases citadas (resposta e recuperação), alguns estudos já indicam essa tendência. Casos específicos abordados por Siena (2012) e Santos et

\footnotetext{
${ }^{9}$ As ações de prevenção, mitigação e preparação são anteriores ao impacto e visam eliminar, minimizar e preparar as pessoas para os riscos/impactos. As duas últimas, resposta e recuperação, referem-se ao impacto e pós-impacto. As ações de resposta são realizadas para o socorro e a assistência aos afetados; as ações de recuperação são voltadas para recuperação do local, de suas atividades e serviços.

${ }^{10}$ Para esta questão era possível marcar mais de uma alternativa, gerando um resultado de mais de $100 \%$.
} 


\section{ReVistg ell pautg}

\} A ATUAÇÃO DOS ASSISTENTES SOCIAIS - DUTRA, A. S.; GONÇALVES, R. S.\}

DOI: $10.12957 / R E P .2016 .25388$

al. (2014) tratam da atuação de assistentes sociais no impacto e no pósimpacto. No entanto, a presente pesquisa demonstra uma recorrência desta questão em níveis mais amplos.

Após a ocorrência dos impactos, assistentes sociais deixam sua rotina de trabalho para engrossarem as equipes de atendimento nas diversas emergências que ocorrem todos os anos no contexto nacional. Entre deslizamentos, secas, terremotos e outras situações que geram um grande contingente de desabrigados, desalojados e familiares, estão os assistentes sociais. O caso recente do rompimento das barragens da mineradora Samarco, em Mariana (Minas Gerais) mais uma vez aponta essa realidade. Reportagens diversas citam os assistentes sociais como profissionais atuantes no que já é considerado o maior desastre socioambiental da região ${ }^{11}$.

Tendo em vista que os problemas não cessam com o fim da emergência, muitos casos permanecem sendo acompanhados pelos profissionais no pós-impacto, e o trabalho iniciado logo após o impacto, em geral, perdura por meses ou anos. Os obstáculos enfrentados nos atendimentos, as inúmeras dificuldades de recuperação dos bens perdidos e a morosidade para realocação fazem com que a população afetada se torne usuária quase permanente da Política de Assistência Social e, consequentemente, do Serviço Social.

Voltando aos dados da pesquisa, quando partimos para a análise da prevenção como terceira fase mais citada pelos participantes na atuação dos assistentes sociais, verificamos que esta informação requer uma análise em termos mais gerais, embora ainda no bojo do estudo. A resposta não mantém coerência com a questão a seguir, que trata das atribuições do assistente social na área de riscos e desastres. Nesse caso, verifica-se que apenas 10 dos respondentes apontam ações voltadas para a prevenção, ou seja, o equivalente a 7\% dos municípios. Novamente, ganham relevância os momentos de impacto e pós-impacto já mencionados.

Observa-se uma forte concentração nas ações de resposta e recuperação voltadas para as famílias em risco e/ou afetadas, que vão desde o cadastramento das pessoas, até a gestão de abrigos, passando pelo cadastramento das famílias, pela distribuição de donativos etc. No pós-impacto, ou fase de recuperação, destaca-se o processo de realocação em casas populares. A tabela abaixo ${ }^{12}$ mostra as principais atividades destacadas pelos respondentes em relação às atividades desenvolvidas pelos assistentes sociais na área de riscos e de desastres.

\footnotetext{
${ }_{11}$ Ver reportagens de O Globo (2015) e Folha de São Paulo (2015).

${ }^{12}$ A questão que deu origem a este resultado era aberta. As informações foram organizadas em grandes grupos, de acordo com a semelhança.
} 


\section{ADVistg all paUtg}

\} A ATUAÇÃO DOS ASSISTENTES SOCIAIS - DUTRA, A. S.; GONÇALVES, R. S. \}

DOI: $10.12957 /$ REP.2016.25388

\section{Considerações finais}

Parece correto afirmar que a inexistência de assistentes sociais nos órgãos de Proteção e Defesa Civil e as respostas sobre fases e atribuições profissionais estão diretamente relacionadas. Embora haja a necessidade de um estudo mais aprofundado no que se refere às possíveis diferenças de atuação entre os assistentes sociais lotados em outros órgãos e os profissionais que já compõem as equipes fixas de gestão de riscos e desastres, a ausência do Serviço Social no dia a dia da instituição se apresenta, por um lado, como um forte indicativo da existência de demandas por ações pontuais e descoladas de um processo mais amplo de gestão de riscos e desastres. Por outro lado, essa ausência dificulta uma reflexão mais crítica sobre os limites e desafios da Política Nacional de Proteção e Defesa Civil e de sua implementação (BRASIL, 2012).

A participação dos assistentes sociais nos desastres tem se dado por vinculações institucionais mais indiretas, ou seja, menos pela sua ligação formal com os órgãos responsáveis pela gestão - a exemplo das Defesas Civis municipais - e mais por meio dos quadros profissionais das Secretarias responsáveis pelo Desenvolvimento social local - acionados quase sempre em caráter emergencial - e ainda, por vezes e mais indiretamente, por intermédio de entidades de natureza filantrópica que na etapa do socorro se somam ao trabalho social efetivado em prol dos afetados. Não vamos nos deter nesse aspecto, mas apenas realçar que essas diferentes formas de vinculação são determinantes das possibilidades interventivas dos profissionais, relativizando seu poder, autonomia e sua contribuição ao processo de gestão social como um todo. (VARGAS, 2015, p. 133).

Corroborando com essa reflexão, na medida em que estes profissionais não fazem parte dos quadros de Defesa Civil e outros órgãos, setores, gerências ou instituições que se dedicam à discussão/atuação cotidiana na gestão de riscos e de desastres, a possibilidade de só serem "lembrados" nos momentos em que as situações de emergência ocorrem é muito grande, levando a intervenções pontuais e descontinuadas. Nestes casos, o profissional é chamado a desempenhar um papel somente na emergência, mas não a participar das etapas que antecedem o evento físico causador do desastre. A partir dessa lógica, o conhecimento mais aprofundado sobre a área, a atuação na prevenção de riscos e o conhecimento e atuação no gerenciamento dos desastres, propriamente, ficam comprometidos.

Esta inclusão precária aumenta o perigo de enveredar pela racionalidade hegemônica que prevalece nesse meio e que é representada por diversos atores do mundo técnico, perito/científico (VARGAS, 2013). Nesse sentido, não é incomum assistirmos à reprodução, por parte de profissionais, 
de posicionamentos pautados em preconceitos, fortalecendo o discurso oficial junto à população ${ }^{13}$

Para fazer frente a esses desafios, torna-se fundamental que haja um investimento sólido da categoria no tema, articulando as diferentes dimensões que constituem o Serviço Social para que seja possível compreender a gestão de riscos e desastres em suas variadas nuances, permeada por interesses e concepções de mundo distintas. Vale lembrar que se trata de uma profissão marcada pelo contato direto com as classes subalternas, que tem como um de seus princípios fundamentais a defesa intransigente dos direitos humanos, conforme explicitado no Código de Ética vigente. A atuação de assistentes sociais na garantia de direitos se materializa por meio da elaboração, execução e avaliação de políticas públicas, viabilização de acesso dos usuários a estas políticas e, dentre outras ações, democratização da informação.

Nas quatro últimas décadas, a categoria tem procurado apreender a estrutura da sociedade capitalista, assim como as relações sociais estabelecidas neste sistema, com o intuito de compreender criticamente as demandas colocadas para a profissão de forma a qualificar sua intervenção. A dimensão educativa presente na atuação do Serviço Social faz deste profissional um agente de mudanças que vem ampliando sua intervenção e voltando-a para um aspecto também preventivo. Assim como nas demais áreas de atuação, tal desafio também está presente na gestão de riscos e de desastres.

\footnotetext{
${ }^{13}$ Foge aos objetivos e limites da pesquisa em questão um estudo mais aprofundado sobre este fazer profissional. No entanto, para além das atividades que são realizadas por estes profissionais, cabe uma investigação sobre a forma como o trabalho é realizado e a que projetos tem servido.
} 


\section{heVistg all pautg}

\} A ATUAÇÃO DOS ASSISTENTES SOCIAIS - DUTRA, A. S.; GONÇALVES, R. S.\}

DOI: $10.12957 /$ REP.2016.25388

\section{Referências}

BRASIL. Decreto n. 12.628 de 17 de junho de 1943. 1943a. Disponível em: <http://www2. camara.leg.br/legin/fed/decret/1940-1949/decreto12628-17-junho-1943-461366-publicacaooriginal-1-pe.html>. Acesso em: 26 out. 2015.

. Decreto-Lei n. 5.861 de 30 de setembro de 1943. 1943b. Disponível em: <http:// www2.camara.leg.br/legin/fed/declei/1940-1949/decretolei-5861-30-setembro-1943-416012-publicacaooriginal-1-pe.html>. Acesso em: 26 out. 2015.

. Decreto federal n. 64.568 de 22 de maio de 1969. 1969. Disponível em <http:// www2.camara.leg.br/legin/fed/decret/1960-1969/decreto64568-22-maio-1969-405974-publicacaooriginal-1-pe.html> Acesso em: 27 out. 2015.

. Decreto-Lei federal n. 83.839/79. 1979. Disponível em: <http:// www2.camara. leg.br/legin/fed/decret/1970-1979/decreto-83839-13agosto-1979-433244-publicacao original-1-pe.html> Acesso em: 15 nov. 2014.

. Decreto federal n. 97.274 de 16 de dezembro de 1988. 1988. Disponível em: <http://www.planalto.gov.br/ccivil_03/decreto/D97274. htm>. Acesso em: 10 nov. 2015.

. Política Nacional de Proteção e Defesa Civil. Brasília: Diário Oficial da União, 11 abr. 2012.

. Ministério da Integração Nacional. Portal. Disponível em: <http:// www.defesacivil.gov.br/comunidade/index.asp>. Acesso em: 23 de set. 2012.

COUTO, B. R. et al. A política nacional de assistência social e o Suas: apresentando e problematizando fundamentos e conceitos. In: COUTO, B. R. et al. (Org.) O Sistema Único de Assistência Social no Brasil: uma realidade em movimento. São Paulo: Cortez. 2014.

DUTRA, A. D.; DALCIN, K. C. Serviço Social, emergências e desastres: notas sobre a atuação profissional. In: DOHER, I. (Org.). O Serviço Social em empresas para além da crítica: espaços de enfrentamento e atuação profissional. Rio de Janeiro: E-papers. 2015.

FOLHA DE SÃO PAULO. Familiares de operários que estavam trabalhando na barragem reclamam de falta de informação. 2015. Disponível em: <http:/ /m.folha.uol.com.br/cotidiano/2015/11/1703818-familiares-dos-operariosque-estavam-na-barragem-reclamam-de-falta-de-informacao.shtml? mobile>. Acesso em: 10 de nov. 2015. 


\section{ReVistg ell pautg}

\} A ATUAÇÃO DOS ASSISTENTES SOCIAIS - DUTRA, A. S.; GONÇALVES, R. S. \}

DOI: $10.12957 / R E P .2016 .25388$

MARCELINO, E. V.; NUNES, L. H.; KOBIYAMA, M. Banco de dados de desastres naturais: análise de dados globais e regionais. Caminhos de Geografia, v. 7, n. 19. 2006.

NATENZON, C.; VIAND, J. M. Gestión de los desastres em Argentina: instituciones nacionales involucradas em la problemática de las inundaciones. América Latina: Sociedade e Meio Ambiente. 2008.

NETTO, J. P. Introdução ao método da teoria social. In: Serviço Social: direitos sociais e competências profissionais. Brasília: CFESS/Abepss. 2009.

O ESTADO DE SÃO PAULO. Brasil admite à ONU despreparo em tragédias. São Paulo, 15 jan. 2011. Disponível em: <http://www.estadao.com.br/no ticias/geral,brasil-admite-a-onudespreparo-em-tragedias,666923,0.htm>. Acesso em: 8 maio. 2012.

O GLOBO. Jovem de São Carlos trabalha como voluntária em tragédia de Mariana. 2015. Disponível em: <http://g1.globo.com/sp/sao-carlos-regiao/ noticia/2015/11/jovem-de-sao-carlos-trabalha-como-voluntaria-emtragedia-de-mariana.html>. Acesso em: 10 nov. 2015.

RIO DE JANEIRO (Estado). Histórico e evolução da Defesa Civil no Brasil. Rio de Janeiro: Secretaria de Estado da Defesa Civil. 1999. Disponível em: <http://www2.cbmerj.rj.gov.br/index.php?option=com_content\&view $=$ article $\&$ id $=192$ : historico-e-evolucao-da-defesa-civil-no-brasil \&catid=7:Informacoes-Tecnicas\&ltemid=15. Acesso em: 15 set. 2015.

SANTOS, A. R. et al. A intervenção estatal em situações de desastres naturais: uma análise do papel da política de assistência social. In: CARMO, R.; VALENCIO, N. (Org.). Segurança humana no contexto dos desastres. São Carlos: Rima. 2014.

SANTOS, R. Gestão de desastres e política de assistência social. Revista Katálysis, Florianópolis, v. 15, n. 1. 2012.

SIENA, M. A atenção social nos desastres: uma análise sociológica das diversas concepções de atendimento aos grupos sociais afetados. Tese (Doutorado - Programa de Pós-Graduação em Sociologia). São Carlos, UFSCar. 2012.

UFSC. Universidade Federal de Santa Catarina. Capacitação básica em Defesa Civil. Florianópolis: CAD UFSC. 2013.

VALENCIO, N. et al. (Org.) Sociologia dos desastres: construção, interfaces e perspectivas no Brasil. São Carlos: Rima. 2009.

VALENCIO, N. Desastres, ordem social e planejamento em Defesa Civil: o contexto brasileiro. Saúde e Sociedade, São Paulo, v. 19, n. 4. 2010.

2012.

. Para além do "dia do desastre": o caso brasileiro. Curitiba: Appris. 


\section{heVistg all pautg}

\} A ATUAÇÃO DOS ASSISTENTES SOCIAIS - DUTRA, A. S.; GONÇALVES, R. S.\}

DOI: $10.12957 /$ REP.2016.25388

VARGAS, M. A. R. A construção social da moradia de risco. Revista Brasileira de Estudos Urbanos e Regionais, v. 8, n. 1. 2006.

. Da "chuva atípica" à "falta de todo mundo": a luta pela classificação de um desastre no município de Teresópolis/RJ. Tese (Doutorado - Programa de Programa de Pós-Graduação em Sociologia). São Carlos, UFSCar. 2013. . Reino da necessidade versus reino dos direitos: desafios e impasses ao assistente social em contextos de desastres. In: SIQUEIRA, A. et al. Riscos de desastres relacionados à água. São Carlos: Rima. 2015.

VASCONCELOS, A. M. A prática do Serviço Social: cotidiano, formação e alternativas na área da saúde. São Paulo: Cortez. 2007.

Recebido em 24 de abril de 2016.

Aprovado para publicação em 24 de junho de 2016.

DOI: $10.12957 /$ rep.2016.25388

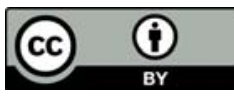

A Revista Em Pauta: Teoria Social e Realidade Contemporânea está licenciada com uma Licença Creative Commons Atribuição 4.0 Internacional. 